\title{
Optimal Power Flow Improvement Using a Hybrid Teaching-Learning-based Optimization and Pattern Search
}

\author{
Belkacem Mahdad \\ Department of Electrical Engineering, University of Biskra, Algeria \\ Email: bemahdad@yahoo.fr \\ Kamel Srairi \\ Department of Electrical Engineering, University of Biskra, Algeria \\ Email: ksrairi@mselab.org
}

Received: 22 November 2017; Accepted: 17 January 2018; Published: 08 March 2018

\begin{abstract}
In this paper a novel flexible planning strategy based on the teaching-learning-based optimization (TLBO) algorithm and pattern search algorithm (PS) is proposed to improve the security optimal power flow (SOPF) by minimizing the total fuel cost, total power loss and total voltage deviation considering critical load growth. The main particularity of the proposed hybrid method is that TLBO algorithm is adapted and coordinated dynamically with a local search algorithm (PS). In order validate the efficiency of the proposed strategy, it has been demonstrated on the Algerian 59-bus power system and the IEEE 118-bus for different objectives considering the integration of multi SVC devices. Considering the interactivity of the proposed combined method and the quality of the obtained results compared to the standard TLBO and to recent methods reported in the literature, the proposed method proves its ability for solving practical planning problems related to large power systems.
\end{abstract}

Index Terms-Power system planning, Optimal power flow, Teaching-Learning (TLBO), Pattern search, Hybrid method, Power loss, Voltage deviation, SVC.

\section{INTRODUCTION}

The famous OPF formulation firstly introduced by Dommel et.al [1] has been successfully solved more than fifty years using several classical optimization techniques such as linear programming (LP) [2], nonlinear programming (NLP) [3], quadratic programming (QP) [4], Newton method [5] and interior point method [6]. However by considering the non-linear characteristics of thermal units and with excessive installation of multi type of FACTS devices and renewable sources in modern power system, the conventional optimization technique fail to solve with accuracy the complex OPF for large power systems. To overcome the inherent limitations of determinist methods, metaheuristic methods have been developed. In the literature a large number of standard metaheuristic optimization methods and their variants have been applied to solve many optimization problems related to modern power systems. In [7] an improved genetic algorithm is applied to solve the OPF under normal and abnormal conditions such as contingency. In [8] a parallelism concept is introduced based on GA named decomposed parallel GA is applied to solve the OPF considering environmental constraints and SVC devices. In [9] a variant method based on genetic algorithm and fuzzy rules is proposed to improve the solution of the OPF of the electrical Algerian network. Recently, many new swarm intelligence methods have been developed to solve various problems related to security OPF, the modified mechanism search of these methods tries to create diversity in search space. In [10] Glowworm Swarm optimization is applied to solve the OPF by considering the fuel cost and gaz emission. In [11] a differential evolution is adapted and proposed for solving multi-objective optimal power flow problem. In [12] an improved strength Pareto evolutionary algorithm is proposed to solve the multi-objective OPF by considering the fuel cost and emission. In [13] an efficient Gbest-guided artificial bee colony algorithm is applied for solving the OPF by considering the effect of temperature, the efficiency of the algorithm verified on a large test systems. In [14] the OPF constrained transient stability is solved using the oppositional krill herd algorithm (OKHA). In [15] a backtracking search algorithm (BSA) is proposed to solve the OPF of twoterminal HVDC systems. In [16] a BAT search algorithm is proposed to solve the OPF in the presence of unified power flow controller (UPFC). In [17] an enhanced selfadaptive differential evolution with mixed crossover (ESDE-MC) algorithm is applied to solve the multiobjective OPF. In [18], the concept of Fuzzy logic is adapted with harmony search algorithm to solve the security OPF considering the integration of FACTS devices. In [19] an adaptive real coded biogeography (ARCBBO) is proposed to solve the OPF considering the 
deregulated aspect of practical power system. In [20] a TLBO is applied to solve the OPF problem. In [21] a new algorithm named league championship algorithm (LCA) is applied to solve the OPF of the Algerian power system. In [22] a Hybrid approach based on combination between the min cut algorithm, tangent vector technique and cuckoo search algorithm is applied to improve the power system security via optimal installation of FACTS devices. In [23] a learning DE-APSO-PS strategy is proposed to solve the multi objective large power system planning under sever loading condition and in [24] a black-hole-based optimization approach is proposed to solve the OPF. The analysis of the results of these new optimization techniques in terms of solution quality and number of generation required clearly shows that are efficient and competitive compared to the results of mathematical methods and the standard metaheuristic techniques. However the majority of these methods also require a good choice of their particular control parameters and a flexible interaction between diversification and intensification stages to achieve the best desired solution.

TLBO is one of the recent metaheuristic algorithms firstly introduced by Rao et al. [25] inspired from the interaction between the teacher and the students characterized by two phases, the teacher phase and the interaction between the students themselves called the learners phase. This method attracted many researchers for its simplicity to program and also has a significant advantage such as a few parameters to adjust compared to other metaheuristic methods. The standard TLBO algorithm and only a few developed variants based TLBO have been applied to solve practical power system problems, some of these contributions are cited in $[26,27]$.

In this paper, a hybrid optimization method based TLBO and PS is proposed to solve the OPF problem considering critical load growth. The TLBO is considered as a global search algorithm and PS is considered as a local search mechanism. The main contributions of this paper are summarized as follows:

1. The global search mechanism known as TLBO is chosen for its simplicity and has no parameters to adjust.

2. An interactive local search mechanism based pattern search algorithm is adapted to interact dynamically with TLBO stages during generation. The PS adapted to achieve a perfect exploitation task.

3. The efficiency of the proposed hybrid approach has been verified to many test systems, the Algerian electrical test system 59-Bus and to the IEEE 118Bus with different objective functions at normal condition and considering critical load growth.

4. To enhance the solution quality, practical interactive rules are executed on different stages between TLBO and PS to assist the communication between sub optimal solutions found during search process.

\section{Standard Multi ObJective OPF StRategy}

The main task of OPF strategy is to optimize specified control variables to minimize a particular objective function, while keeping security constraints formulated as equality and inequality constraints in their admissible limits [23]. The problem can be formulated as follows:

$$
\operatorname{Min} J(X, U)
$$

Subject to:

$$
\left\{\begin{array}{l}
g(X, U)=0 \\
h(X, U) \leq 0
\end{array}\right.
$$

where $J_{i}$ is the particular objective function, $\mathrm{g}$ and $\mathrm{h}$ are the security constraints expressed in equality and inequality constraints, $X$ is the vector of state variables and $U$ is the vector of specified control variables.

The vector of state variables is given as follows:

$$
X=\left[\delta, V_{L}, P_{G s}, Q_{G}\right]
$$

The vector of state variables consists of the angles $\delta$ and voltage magnitudes $V_{L}$ of the load buses, the real power of slack generator $P_{G s}$, and the reactive power of control buses $Q_{G}$.

The vector of control variables is expressed by:

$$
U=\left[P_{G}, V_{G}, B_{s h}, B_{s v c}, T\right]
$$

The vector of control variables $U$ is optimized to minimize a specified objective function. The vector of control variables consists of, real power $P_{G}$ and voltage magnitudes $V_{G}$ of generation units, the capacitive susceptance or inductive susceptance of classical compensators $B_{s h}$, the susceptance of shunt static VAR Controllers (SVC) $B_{s v c}$, and the transformers tap ratio $T$.

\subsection{Objective Functions}

\subsubsection{Total Fuel Cost}

The expression of total fuel cost to be optimized is usually formulated using the following objective function.

$$
J_{1}(X, U)=\sum_{i=1}^{N G}\left(a_{i}+b_{i} P_{G i}+c_{i} P_{G i}^{2}\right)+\text { Penalty }
$$

where $N G$ is the number of thermal units, $P_{G i}$ is the active power the $i t h$ generator and $a_{i}, b_{i}$ and $c_{i}$ are the cost coefficients of the ith generator.

\subsubsection{Voltage Deviation}


Voltage deviation is a very important index which reflects reliability of power system to deliver power quality to consumers. Thus, the well known objective function is expressed as follows:

$$
\begin{gathered}
V D=\sum_{i \in N L}\left|V_{i}-V_{\text {ref }}\right| \\
J_{2}(X, U)=V D+\text { Penalty }
\end{gathered}
$$

where $V_{r e f}$ is the desired voltage at load buses.

\subsubsection{Total Power Losses}

The mathematical expressions of total power loss to be optimized are expressed as follows:

$$
\begin{gathered}
P_{\text {loss }}=\sum_{k=1}^{N_{l}} g_{k}\left[\left(t_{k} V_{i}\right)^{2}+V_{j}^{2}-2 t_{k} V_{i} V_{j} \cos \delta_{i j}\right] \\
J_{3}(X, U)=P_{\text {loss }}+\text { Penalty }
\end{gathered}
$$

where $g k$, is the conductance of the $k t h$ branch, $t k$, is the tap ration of the $k t h$ transformer.

\subsubsection{Total Voltage Deviation in Coordination with Total Cost}

The combined objective function to be optimized is formulated using the following expression:

$$
J_{4}(X, U)=\left(\sum_{i=1}^{N G}\left(a_{i}+b_{i} P_{G i}+c_{i} P_{G i}^{2}\right)\right)+\beta .(V D)+\text { Penalty }
$$

where $\beta$ is a penalty factor.

\subsubsection{Load Growth}

The critical load growth is determined by performing load growth at all load bus to achieve the critical point of collapse [23]. The following equation describes the loading margin stability index.

$$
\begin{gathered}
S_{\text {new }}=\lambda \cdot S_{\text {base }} \\
J_{5}(X, U)=\operatorname{Max}(\lambda)
\end{gathered}
$$

where $S_{\text {new }}, S_{\text {base }}$ are the new apparent power and base apparent power demands respectively and $\lambda$ is the critical loading factor.

\subsection{Equality Constraints}

The balance between production and consummation must be maintained at equilibrium state. The two generalized equality constraints known as active and reactive power equilibrium are expressed as follows:

$$
\begin{aligned}
& P_{G i}-P_{D i}-V_{i} \sum_{j=1}^{N b} V_{j}\left(G_{i j} \cos \theta_{i j}+B_{i j} \sin \theta_{i j}\right)=0 \\
& Q_{G i}-Q_{D i}-V_{i} \sum_{j=1}^{N} V_{j}\left(G_{i j} \sin \theta_{i j}-B_{i j} \cos \theta_{i j}\right)=0
\end{aligned}
$$

where $N b$ is the number of buses, $P_{G i}, Q_{G i}$ are the active and the reactive power of the $i t h$ generator; $P_{D i}, Q_{D i}$ are the active and the reactive power demand at the ith load bus; $V_{i}, V_{j}$, the voltage magnitudes at bus $i, j$, respectively; $\theta_{i j}$ is the phase angle difference between buses $i$ and $j$ respectively, $G_{i j}$ and $B_{i j}$ are the conductance and susceptance part of the admittance $\left(Y_{i j}\right)$.

\subsection{Inequality Constraints}

In general, these inequality constraints are organized as follows:

\section{a. Generator Constraints}

- Voltage magnitudes of generating units:

$$
V_{G i}^{\min } \leq V_{G i} \leq V_{G i}^{\max }, i=1,2, \ldots, N P V
$$

- Real power limits of generating units:

$$
P_{G i}^{\min } \leq P_{G i} \leq P_{G i}^{\max }, i=1,2, \ldots, N P V
$$

- $\quad$ Reactive power limits of generating units

$$
Q_{G i}^{\min } \leq Q_{G i} \leq Q_{G i}^{\max }, i=1,2, \ldots, N P V
$$

\section{b. Transformer Constraints}

- Tap ratio (t) of transformer limits.

$$
t_{i}^{\min } \leq t_{i} \leq t_{i}^{\max }, i=1,2, \ldots, N T
$$

\section{c. SVC Constraints}

- Limits on susceptance of SVC Controllers.

$$
B_{s v c}^{\min } \leq B_{s v c} \leq B_{s v c}^{\max } i=1,2, \ldots, N S V C
$$

\section{d. Security Limits}

The security constraints associated to transmission lines and load buses are as follows:

$$
\begin{gathered}
S_{l i} \leq S_{l i}^{\max }, i=1,2, \ldots, N B R \\
V_{L i}^{\text {min }} \leq V_{L i} \leq V_{L i}^{\max }, i=1,2, \ldots, N P Q
\end{gathered}
$$


where; $N P V$, is the number of control buses containing the generators, $N P Q$, is the number of load buses, $N T$, is the number of transformer tap settings, $N B R$, is the number of transmission lines and NSVC is the number of SVC devices.

\subsection{Constraints Management}

To relieve violation of various constraints; the proposed augmented objective function is expressed as follows [28]:

$$
\begin{gathered}
J_{\text {augmented }}(X, U)=J(x, u)+\text { Penalty } \\
\text { Penalty }=\lambda_{v} \sum_{i=1}^{N L}\left(V_{L i}-V_{L i}^{l i m}\right)^{2}+\lambda_{Q} \sum_{i=1}^{N G}\left(Q_{G i}-Q_{G i}^{l i m}\right)^{2} \\
+\lambda_{P}\left(P_{G s}-P_{G s}^{l i m}\right)^{2}+\lambda_{b r} \sum_{i=1}^{N B R}\left(S_{b r i}-S_{b r i}^{l i m}\right)^{2}
\end{gathered}
$$

where $\lambda_{v}, \lambda_{Q}, \lambda_{P}$ and $\lambda_{b r}$ are penalty factor terms, associated to dependent [28].

\section{StATIC VAR COMPENSATOR (SVC)}

The SVC [23] is a shunt FACTS device. As well illustrated in Fig 1, the SVC device has the ability to exchange in real time reactive power with the power system, to control with flexibility voltage at specified bus.

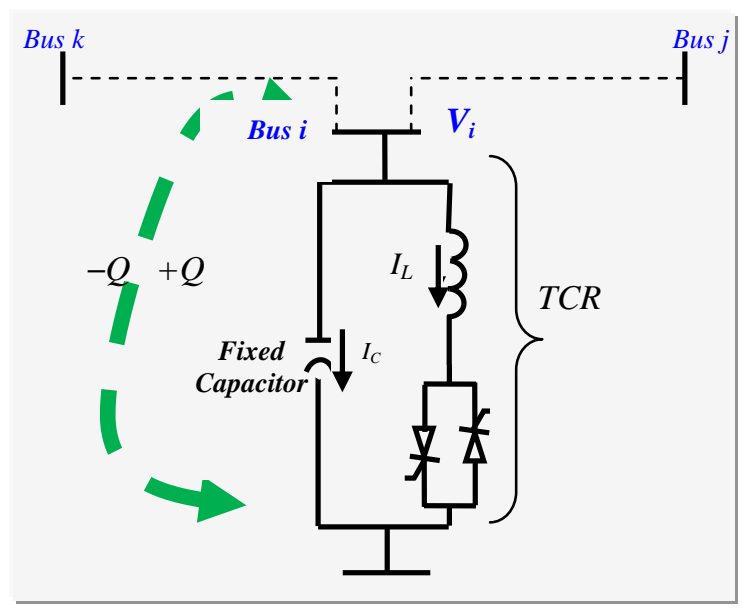

Fig.1. Basic circuit representation of SVC.

The well known SVC model based on variable susceptance is used in this study. SVC allows injecting or absorbing reactive power with the network. The following equations describe the simplified SVC model.

$$
I_{S V C}=j B_{S V C} \times V
$$

The reactive power $Q_{i}^{S V C}$ exchanged with the network at bus i is expressed as:

$$
Q_{i}^{S V C}=B_{i}^{S V C} \times V_{i}^{2}
$$

\section{Global Search Optimization Using Teaching- LEARNING-BASED OPTIMIZATION (TLBO)}

TLBO is a nature-inspired metaheuristic method introduced recently by Rao et al. [25]. Compared to other techniques, TLBO does not require adjusting of parameters and only requires specifying standard parameters such as population size and number of iterations for its operation [25]. The principle of this method is inspired from education, on the effect of influence of a teacher on learners and the effect of learners each other [26]. The mechanism search of TLBO algorithm is elaborated within two interactive phases. The first phase consists of improving knowledge from teacher named as "Teacher Phase" and the second phase consists of improving knowledge from interaction between learners named as "Learner Phase".

\subsection{TLBO Algorithm}

The mechanism search of TLBO consists of two coordinated phases:

\subsubsection{Teacher Phase}

The main task of a good teacher is to bring the level of learners to his level of knowledge, and to facilitate the thinking process. Teaching experience confirmed that the objectives of this task are not easy to achieve, because the levels of students in a classroom is not identical, it depends on their personal efforts, aptitudes and their commitment to learn. Thus, a teacher can only increase the mean level of his/her learners [25, 26]. Exchanging information between learners (students) depends on teacher capability and methodology applied. Fig 2 shows the well known three educational strategies, the classical methodology based on transmission of knowledge from teacher to students without feedback (interactivity) between teacher and students cannot achieve the optimal desired objectives.

Our personal teaching experience confirmed that feedback from learners enhance the performances of the education level. The interactive communication between teacher and learners offers a chance to other isolated elements to interact and develop new and original ideas. The Flowchart of the standard TLBO algorithm is well illustrated in Fig 3. 


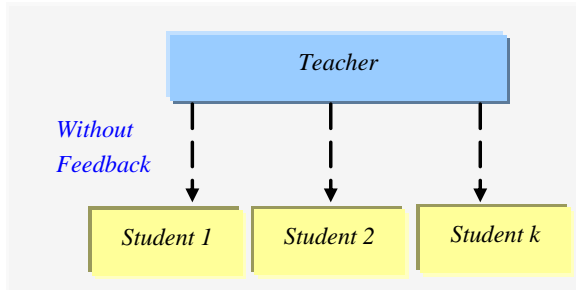

a)
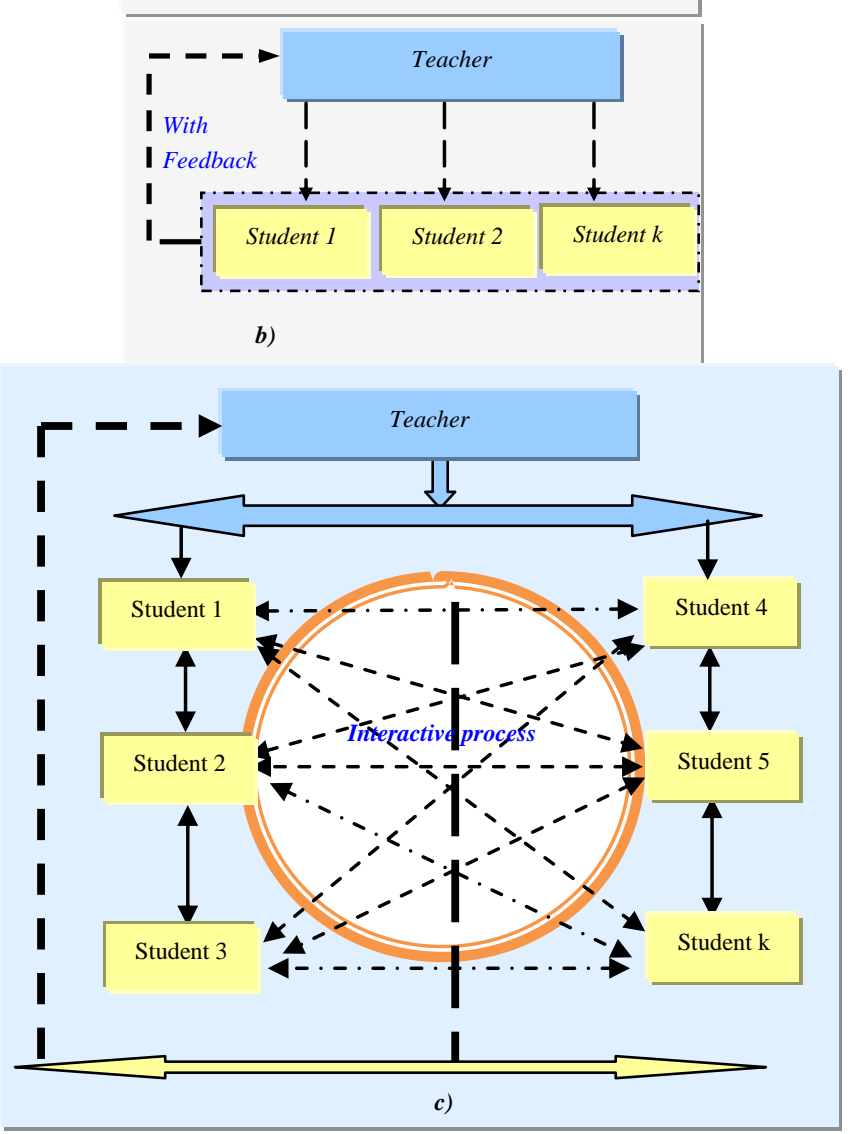

Fig.2. a) Teaching operation without feedback, b) Teaching operation with standard feedback, c) Teaching operation with feedback based on intensive interactive communication. 


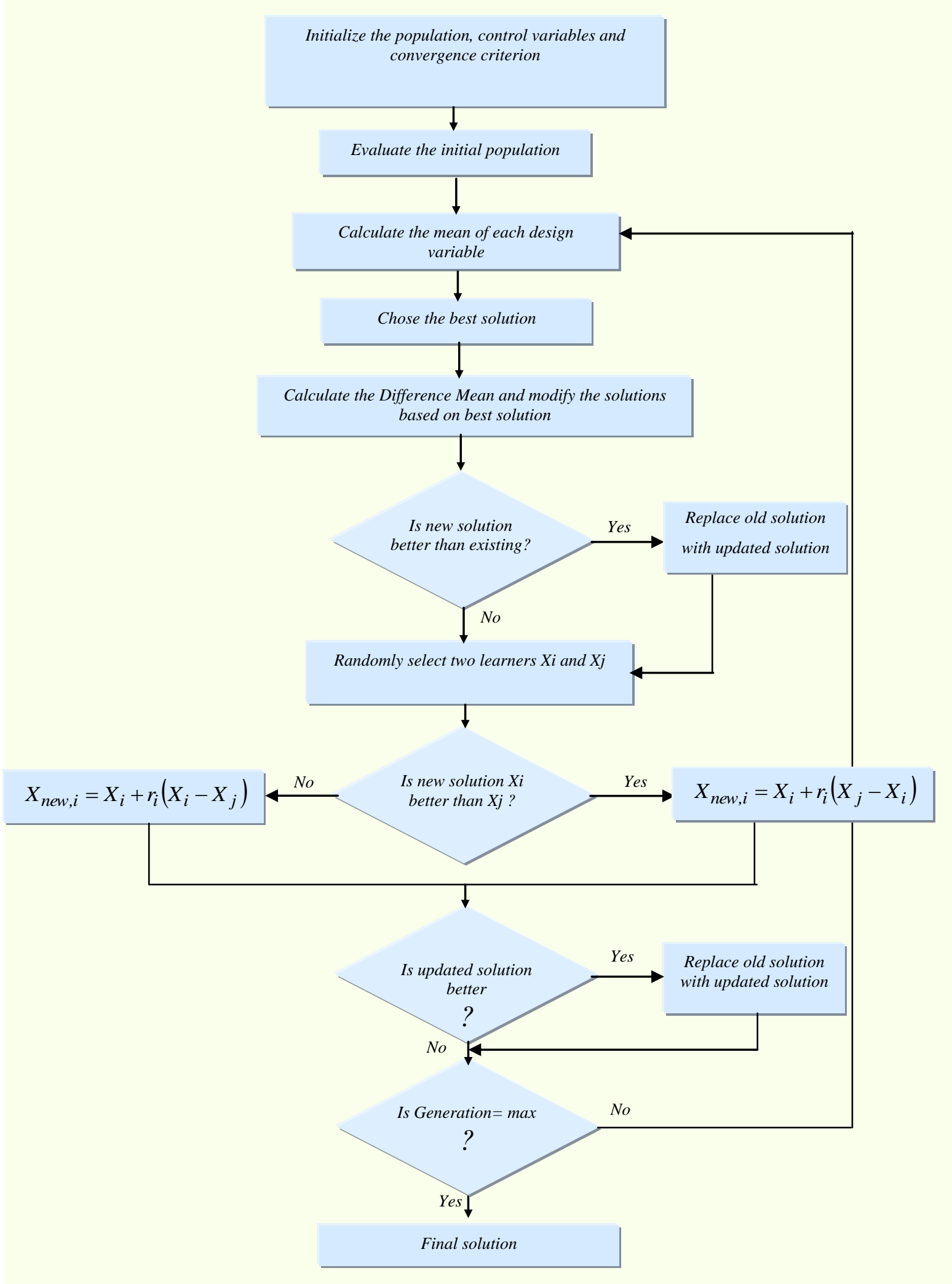

Fig.3. Flowchart of the original TLBO algorithm. 
The standard teaching phase formulated as an optimization algorithm is described based on the following steps [25]:

Step 1: Let $M_{i}$ be the mean of the class and $T_{\text {best }, i}$ is the best solution so far. Hence, $T_{b e s t, i}$ will try to move the mean $M_{i}$ of the class found at specified iteration towards its own level. Thus $T_{\text {best }, i}$ will be the new mean designed as $M_{n e w, i}$. The following equation describes the difference between the old mean and the new mean expressed by [26]:

$$
\operatorname{Diff}_{i}=\operatorname{rand}_{i}\left(M_{n e w, i}-T_{F} M_{i}\right)
$$

Where $T_{F}$ is a teaching factor that weight the actual mean value, this factor can be either 1 or 2 , which is determined using a random process with equal probability expressed by the following equation:

$$
T_{F}=\operatorname{round}[1+\operatorname{rand}(0,1)]
$$

Step 2: the update of solution is evaluated using the following expression [26]:

$$
X_{n e w, i}=X_{i}+\text { Diff }_{i}
$$

$x_{n e w, i}$ is accepted if it improves the fitness value

$$
\begin{aligned}
& \text { if } f\left(X_{n e w, i}\right)<f\left(X_{i}\right) \\
& X_{i}=X_{n e w, i}
\end{aligned}
$$

\subsubsection{Learner Phase}

As well discussed in the above section, a good teacher tries to enhance and increase the knowledge of learners. Teaching methodology confirmed that transmission of knowledge from teacher to learners without interactive communication is not sufficient to achieve the desired objectives. In this second stage the learners enhance their knowledge level through interaction between themselves. A learner in a classroom interacts randomly with other colleagues with the assistance of interactive tools such as a group discussions, presentations, and formal communications. At a specified stage a good learner who knows more than other learners from a group can become a teacher and communicate new ideas to others. The following steps describe the basic learning phase $[25,26]$ :

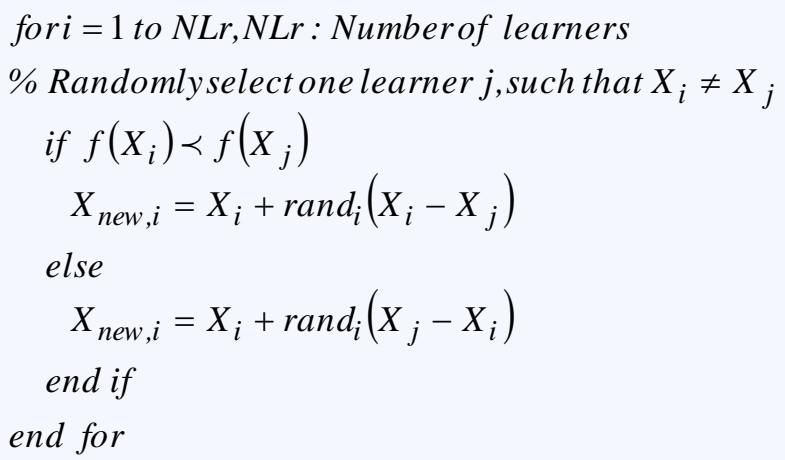

\subsection{Pattern Search Algorithm (PS)}

The pattern search (PS) is an evolutionary algorithm applied to solve various problems related to management of power systems [23]. The potentiality of PS as a local search mechanism when coordinated with global search algorithm has been confirmed in many research results. Fig 4 shows the basic mechanism search of PS.
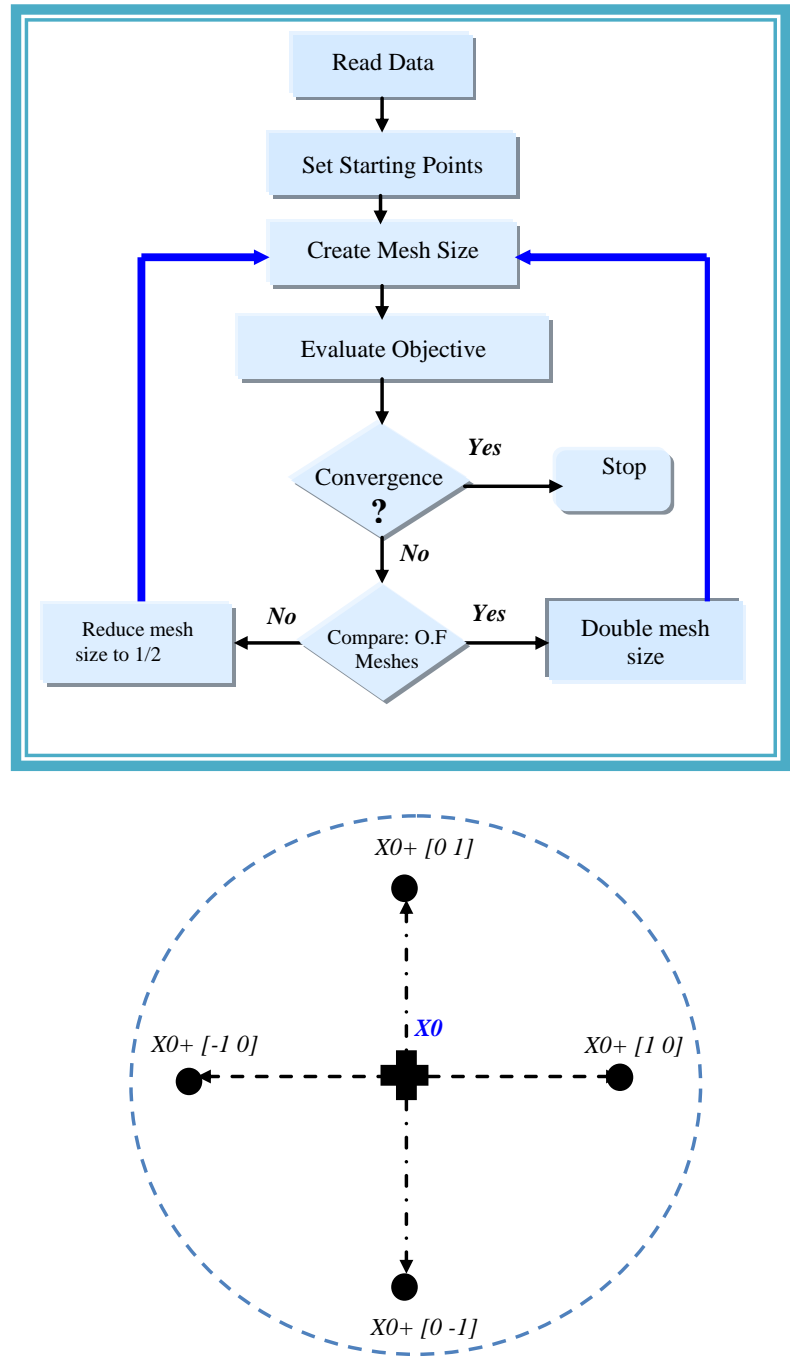

Fig.4. Flowchart of PS algorithm. 
In this study, the particularity of the PS algorithm is investigated as a local search mechanism in combination with TLBO. Details description of direct search methods for solving unconstrained optimization problems may be found in [23].

\section{Proposed Hybrid Optimization Technique}

The main particularity of the proposed hybrid optimization algorithm is to create dynamic and efficient balance between the diversification and intensification stages during search process to avoid trapping into a local optimum. The hybridization between global and local search mechanism allows the algorithm searching a larger and efficient regions to locate the near optimal solution.

\section{A. Methodology of The Proposed Combined Algorithm}

The following points clarify the particularity and initial parameters associated to TLBO and PS algorithms:

1. Adaptation of TLBO algorithm: As well known a method with low parameters to adjust is preferred, in this work, TLBO is chosen and preferred for its remarkable simplicity to adapt and for its few parameters to adjust. In this study TLBO is adapted to achieve the diversification task. The methodology of the proposed combined methods is shown in Fig 5.

2. Adaptation of PS algorithm: PS algorithm is chosen for its simplicity, fast convergence, and also its aptitude for working as a local search mechanism. In this work, the initial parameters of PS are taken as the mesh size and the mesh expansion and contraction factors are selected as 1,2 and 0.5 respectively; the maximum number of iterations is taken between 50 to 150 depending on the complexity of the problem to be solved. PS algorithm is used to achieve a smooth and perfect exploitation task.

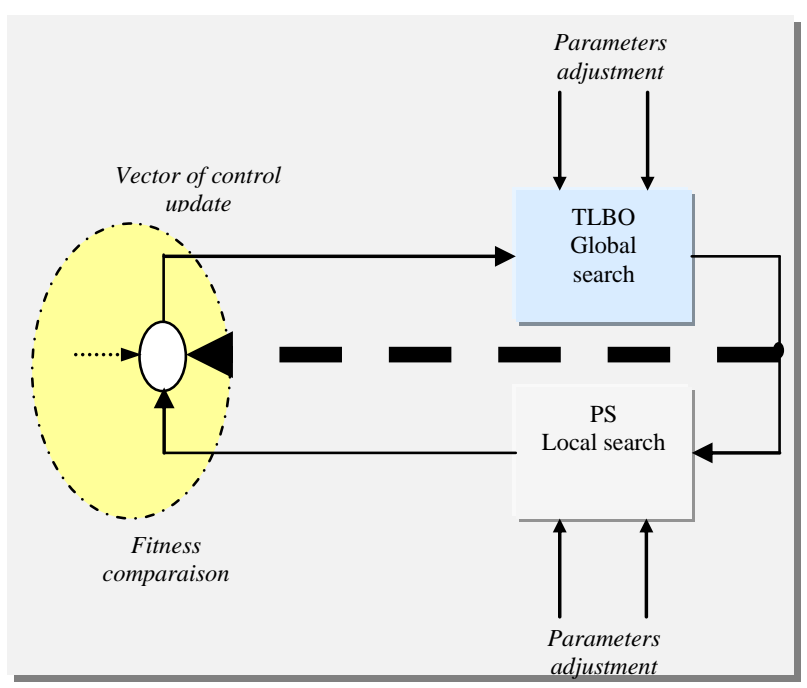

Fig.5. The interaction between global search and local search during search process.

\section{B. Algorithm Steps}

Based on the flowchart of the proposed interactive hybrid method presented in Fig 6, the following steps describe the methodology of the proposed combined algorithm:

1. First stage: For the first trial, generate the first sub optimal solution (database I) related to all proposed objective functions using global search mechanism TLBO. The vector of control variables is saved in a database I.

2. Second stage: Then this solution is transferred to PS algorithm to find near local solution. A new sub optimal solution is generated (database II)

3. Save all control variables corresponding to the best solution.

4. Interactive communication process based on practical rules: After evaluation and during successive trials (trial $>1$ ), practical interactive rules are executed on a sequential manner to assist the communication between sub optimal solutions found using TLBO and PS.

5. The search process repeated until the maximum number of trials chosen.

6. To enhance the efficiency of the original TLBO by creating a dynamic interactivity between learners to generate new ideas (solutions) during search process, the following operator is proposed to create interactivity in global search space:

6.1. Migration operation: For a specified principal objective function $F 1$, the agents of population are randomly perturbed with probability $P m$ based on the sub optimal vector of control variables achieved considering other specified objective functions such as $F 2$, or F3. The migration operation between individuals is an important stage to create equilibrium between diversification and intensification during search process.

6.2. Repeat the same scenario for other objective functions.

6.3 At specified iteration, transmit the best solution to PS.

6.4 Generate new solutions, and save the new vector of control variables including the worst solution.

7. Repeat the communication scenarios until a specified number of trials are achieved.

\section{CASE STUdies}

The efficiency of the proposed approach has been applied and validated on two practical test systems, the real Algerian electrical 59 Bus test system and to the IEEE 118 Bus, data can be retrieved from [8, 9, 23, 28, 29].

> Test System 1: Algerian Network Test: 59-Bus (Sonelgaz Company)

The proposed strategy has been tested on the Algerian power system. It consists of 59 buses, 83 lines and 10 thermal units. Table I shows the technical data of the ten generators, knowing that the generator of the bus $N^{\circ}=13$ is not in service $[8,21]$. For the purpose of verifying the efficiency of the proposed combined approach, we made a comparison of our algorithm with the standard TLBO 
and with others competing OPF algorithms. Six test cases have been considered to validate the robustness of the proposed hybrid technique.

Case 1: Minimization of cost

Case 2: Minimization of voltage deviation

Case 3: Minimization of power loss

Case 4: Minimization of voltage deviation and total cost

Case 5: Minimization of voltage deviation considering loading margin stability

Case 6: Minimization of power losses considering loading margin stability.
Table 1. Parameters of thermal units

\begin{tabular}{cccccccc}
\hline $\begin{array}{c}\text { Unit } \\
\mathrm{N}^{\circ}\end{array}$ & $\begin{array}{c}\text { Pmin } \\
{[\mathrm{MW}]}\end{array}$ & $\begin{array}{c}\text { Pmax } \\
{[\mathrm{MW}]}\end{array}$ & $\begin{array}{c}\text { Vmax } \\
(\mathrm{p} . \mathrm{u})\end{array}$ & $\begin{array}{c}\text { Qmax } \\
{[\mathrm{Mvar}]}\end{array}$ & $\begin{array}{c}\mathrm{a} \\
{[\$ / \mathrm{h}]}\end{array}$ & $\begin{array}{c}\mathrm{b} \\
{[\$ / \mathrm{MWh}]}\end{array}$ & $\begin{array}{c}\mathrm{c} \\
{\left[\$ / \mathrm{MW}^{2} \mathrm{~h}\right]}\end{array}$ \\
\hline 1 & 8 & 72 & 1.1 & 15 & 0 & 1.50 & 0.0085 \\
2 & 10 & 70 & 1.1 & 45 & 0 & 2.50 & 0.0170 \\
3 & 30 & 510 & 1.1 & 55 & 0 & 1.50 & 0.0085 \\
4 & 20 & 400 & 1.1 & 90 & 0 & 1.50 & 0.0085 \\
13 & 15 & 150 & 1.1 & 48 & 0 & 2.50 & 0.0170 \\
27 & 10 & 100 & 1.1 & 35 & 0 & 2.50 & 0.0170 \\
37 & 10 & 100 & 1.1 & 35 & 0 & 2.00 & 0.0030 \\
41 & 15 & 140 & 1.1 & 45 & 0 & 2.00 & 0.0030 \\
42 & 18 & 175 & 1.1 & 55 & 0 & 2.00 & 0.0030 \\
53 & 30 & 450 & 1.1 & 160 & 0 & 1.50 & 0.0085 \\
\hline
\end{tabular}

Red color indicates the limits of control variables.

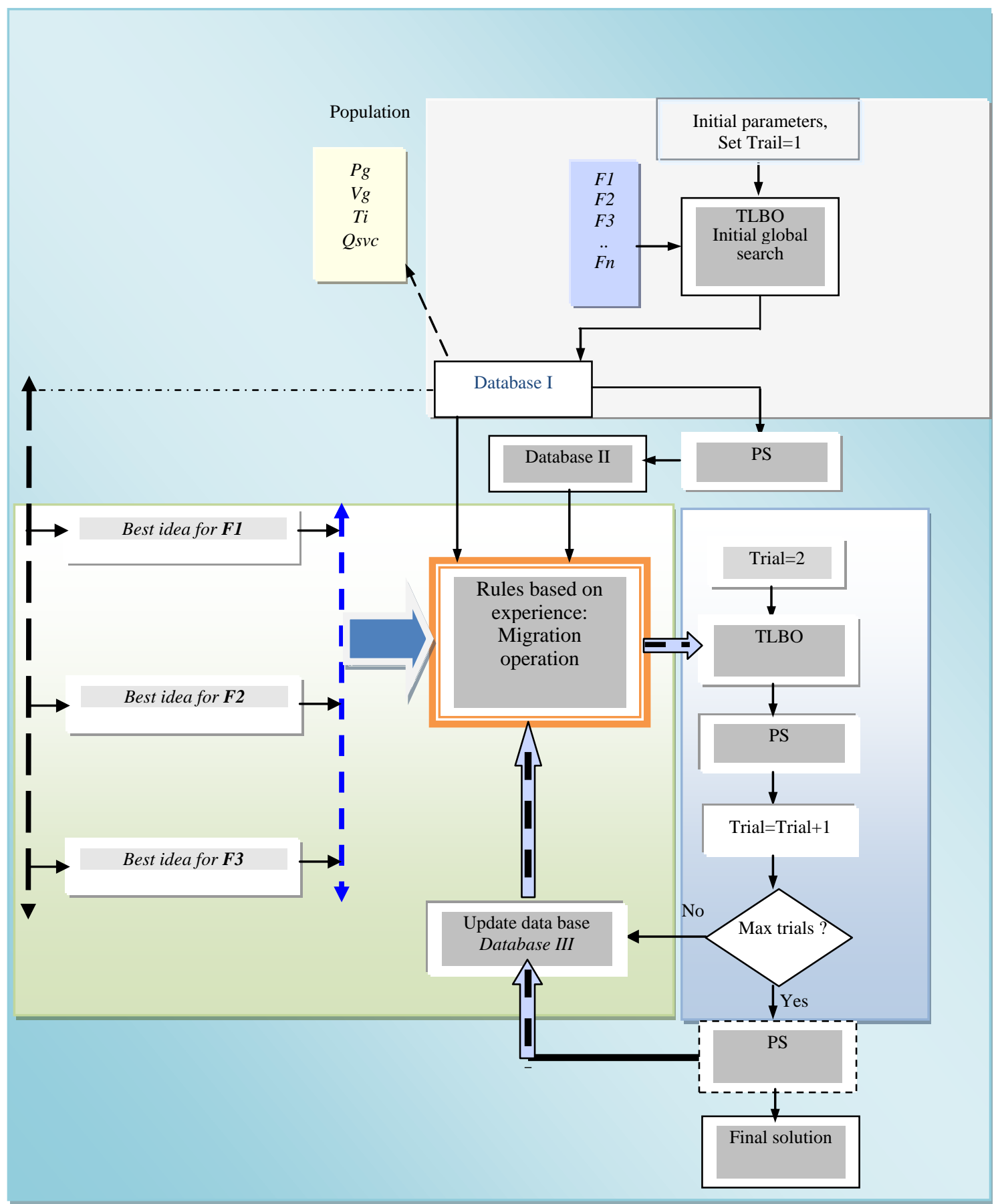

Fig.6. Strategy of the proposed hybrid algorithm 


\subsection{Algerian Network Planning at Normal Condition Without SVC Compensator}

- Case1: Minimization of Fuel Cost With and Without SVC

The objective function considered in this case is the total fuel cost. The optimized vector of control variables is given in Table 2. In order to show the efficiency of the proposed method and as shown in Table 3, the results are compared to the standard TLBO and some other recent techniques reported in the literature. It appears from this comparison that, the proposed approach outperforms the results found using the original TLBO and many other techniques in term of solution quality and convergence characteristics, the best fuel cost achieved is 1690.717 \$/h The convergence characteristics of the fuel cost with and without considering the effect of SVC devices are shown in Fig 7, the optimized convergence characteristics of generating control voltages at the first stage are shown in Fig 8. In this case the total fuel cost is also optimized by considering the integration of SVC compensators at critical buses based on continuation power flow. Four SVC compensators are installed at buses 18, 25, 36, 47 to improve the quality of different objective functions. As we can see in Fig 7, the total fuel cost is reduced to a competitive value $1686.3069 \$ / \mathrm{h}$.

Table 2. Optimal vector of control variables: cases 1-4: without compensation

\begin{tabular}{|c|c|c|c|c|c|c|c|c|}
\hline \multirow{2}{*}{$\begin{array}{l}\text { Control } \\
\text { Variables }\end{array}$} & \multicolumn{2}{|c|}{ Case 1} & \multicolumn{2}{|c|}{ Case 2} & \multicolumn{2}{|c|}{ Case 3} & \multicolumn{2}{|c|}{ Case 4} \\
\hline & TLBO & TLBO-PS & TLBO & TLBO-PS & TLBO & TLBO-PS & TLBO & TLBO-PS \\
\hline $\mathrm{P}_{\mathrm{G} 1}$ & 60.7725 & 60.3359 & 19.5989 & 19.8536 & 22.5298 & 20.9437 & 42.8841 & 42.5694 \\
\hline $\mathrm{P}_{\mathrm{G} 2}$ & 23.2808 & 23.2838 & 10.0001 & 10.0452 & 69.9100 & 69.9076 & 10.0200 & 10.0787 \\
\hline $\mathrm{P}_{\mathrm{G} 3}$ & 101.7724 & 101.7754 & 30.0001 & 30.0452 & 53.7900 & 53.7864 & 30.0300 & 30.0887 \\
\hline $\mathrm{P}_{\mathrm{G} 4}$ & 110.3617 & 110.3647 & 69.0522 & 69.0973 & $\begin{array}{c}149.850 \\
0\end{array}$ & 149.8502 & 107.440 & 107.4987 \\
\hline $\mathrm{P}_{\mathrm{G} 5}$ & 0 & 0 & 0 & 0 & 0 & 0 & 0 & 0 \\
\hline $\mathrm{P}_{\mathrm{G} 6}$ & 25.8546 & 25.8576 & 84.8189 & 84.8640 & 100.000 & 99.9986 & 98.2000 & 98.2587 \\
\hline $\mathrm{P}_{\mathrm{G} 7}$ & 51.0278 & 51.0308 & 41.6393 & 41.6844 & 40.9300 & 40.9258 & 46.4100 & 46.4687 \\
\hline $\mathrm{P}_{\mathrm{G} 8}$ & 96.4420 & 96.4450 & 46.1788 & 46.2239 & 47.7500 & 47.7500 & 61.8000 & 61.8587 \\
\hline $\mathrm{P}_{\mathrm{G} 9}$ & 140.3541 & 140.3571 & 93.7913 & 93.8364 & 108.900 & 108.9025 & 92.6800 & 92.7387 \\
\hline $\mathrm{P}_{\mathrm{G} 10}$ & 103.2693 & 103.2723 & 315.7026 & 315.7477 & 103.900 & 103.9040 & 212.970 & 213.0287 \\
\hline $\mathrm{V}_{\mathrm{G} 1}$ & 1.0838 & 1.0890 & 1.0370 & 1.0261 & 1.0424 & 1.0888 & 1.0820 & 1.0778 \\
\hline $\mathrm{V}_{\mathrm{G} 2}$ & 1.0716 & 1.0768 & 1.0913 & 1.0804 & 1.0970 & 1.0980 & 1.0930 & 1.0888 \\
\hline $\mathrm{V}_{\mathrm{G} 3}$ & 1.0838 & 1.0890 & 1.1000 & 1.0891 & 1.0837 & 1.0998 & 1.1000 & 1.0958 \\
\hline $\mathrm{V}_{\mathrm{G} 4}$ & 1.0640 & 1.0692 & 1.0231 & 1.0122 & 1.0285 & 1.1000 & 1.0130 & 1.0088 \\
\hline $\mathrm{V}_{\mathrm{G} 5}$ & 1.0774 & 1.0826 & 1.0381 & 1.0272 & 1.0435 & 1.1000 & 1.0490 & 1.0448 \\
\hline $\mathrm{V}_{\mathrm{G} 6}$ & 1.0619 & 1.0691 & 1.0216 & 1.0106 & 1.0270 & 1.0983 & 1.0110 & 1.0068 \\
\hline $\mathrm{V}_{\mathrm{G} 7}$ & 1.0838 & 1.0890 & 1.0268 & 1.0159 & 1.0322 & 1.1000 & 1.0100 & 1.0058 \\
\hline $\mathrm{V}_{\mathrm{G} 8}$ & 1.0838 & 1.0890 & 1.0309 & 1.0200 & 1.0363 & 1.0796 & 1.0690 & 1.0648 \\
\hline $\mathrm{V}_{\mathrm{G} 9}$ & 1.0838 & 1.0890 & 1.0605 & 1.0496 & 1.0661 & 1.1000 & 1.0690 & 1.0648 \\
\hline $\mathrm{V}_{\mathrm{G} 10}$ & 1.0833 & 1.0885 & 1.0932 & 1.0823 & 1.0989 & 1.1000 & 1.0930 & 1.0888 \\
\hline PD & 684.1 & 684.1 & 684.1 & 684.1 & 684.1 & 684.1 & 684.1 & 684.1 \\
\hline Cost $(\$ / h)$ & 1691.7 & 1690.717 & 2312.40 & 2314.10 & $\begin{array}{c}1927.10 \\
4\end{array}$ & 1924.10 & 1978.5897 & 1979.4 \\
\hline Power loss & 29.0353 & 28.6226 & 26.6822 & 27.2976 & 13.4598 & 11.8688 & 18.3341 & 18.4891 \\
\hline $\begin{array}{l}\text { (MW) } \\
\text { Voltage } \\
\text { deviation } \\
\text { (p.u) }\end{array}$ & 2.1048 & 2.2444 & 1.8758 & 1.8038 & 2.0290 & 3.0336 & 1.9916 & 1.9686 \\
\hline
\end{tabular}

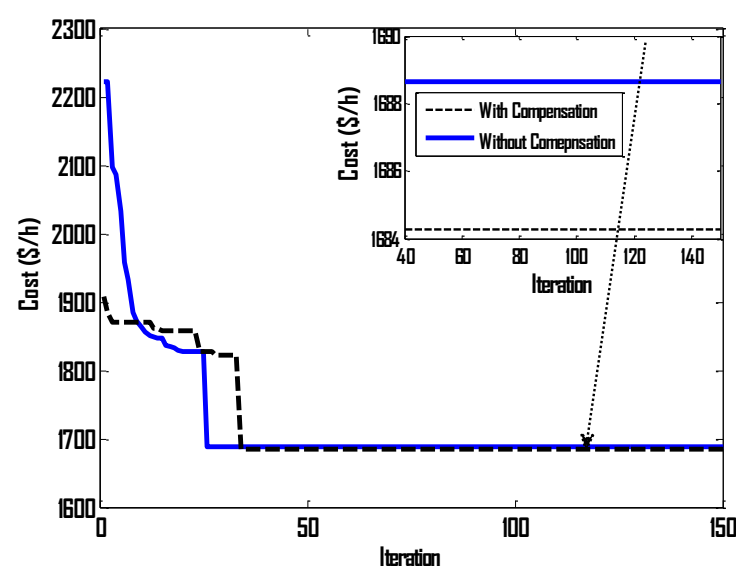

Fig.7. Convergence characteristics of total fuel cost at the final stage: with and without SVC devices.

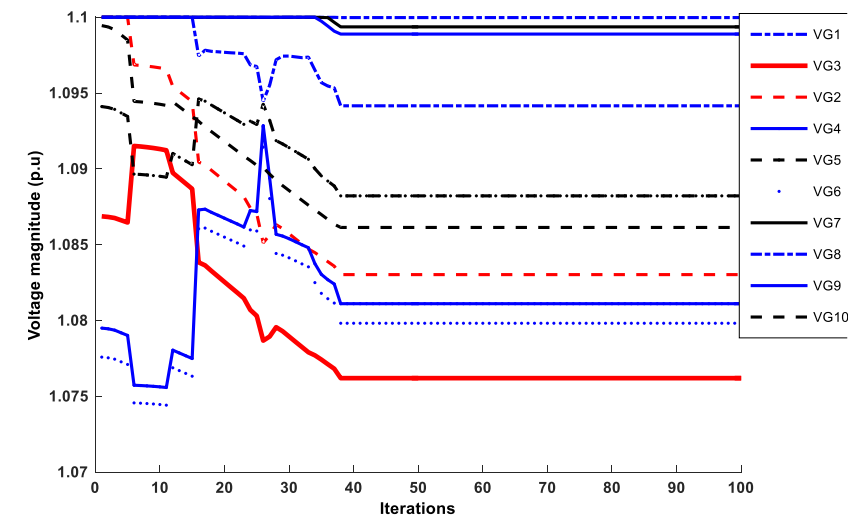

Fig. 8. Convergence characteristics of generating control voltages at the first stage: Case 1. 
Table 3. Comparative study for Case1: minimum of total cost.

\begin{tabular}{|c|c|c|c|}
\hline $\begin{array}{l}\text { Methods }[8,9 \text {, } \\
\text { 20,21, 24] }\end{array}$ & Cost $(\$ / h)$ & $\begin{array}{c}\text { Method } \\
\text { description }\end{array}$ & $\begin{array}{l}\text { Remarks } \\
\text { (limit } \\
\text { violations) } \\
\end{array}$ \\
\hline FGA & 1768.5000 & $\begin{array}{c}\text { Fuzzy } \\
\text { Genetic } \\
\text { Algorithm } \\
\end{array}$ & I \\
\hline GA & 1937.1000 & $\begin{array}{c}\text { Genetic } \\
\text { algorithm }\end{array}$ & I \\
\hline $\mathrm{ACO}$ & 1815.7000 & $\begin{array}{l}\text { Ant Colony } \\
\text { Optimization }\end{array}$ & / \\
\hline FSLP & 1775.8560 & $\begin{array}{c}\text { fast } \\
\text { successive } \\
\text { linear } \\
\text { programming }\end{array}$ & I \\
\hline PGA & 1769.7000 & $\begin{array}{c}\text { Decomposed } \\
\text { Parallel GA } \\
\end{array}$ & I \\
\hline LCA & 1688.5210 & $\begin{array}{c}\text { League } \\
\text { championship } \\
\text { algorithm }\end{array}$ & $\begin{array}{c}\text { Infeasible } \\
\text { solution } \\
\text { violation } \\
\quad \text { of } \\
\text { constraints }\end{array}$ \\
\hline BHBO & 1710.0859 & $\begin{array}{c}\text { Black-Hole- } \\
\text { Based } \\
\text { Optimization } \\
\end{array}$ & 1 \\
\hline $\begin{array}{l}\text { TLBO (without } \\
\text { compensators ) }\end{array}$ & 1691.7000 & $\begin{array}{c}\text { Teaching } \\
\text { learning } \\
\text { based } \\
\text { optimization }\end{array}$ & I \\
\hline $\begin{array}{c}\text { TLBO (with } \\
\text { compensators ) }\end{array}$ & 1688.9000 & $\begin{array}{c}\text { Teaching } \\
\text { learning } \\
\text { based } \\
\text { optimization }\end{array}$ & I \\
\hline $\begin{array}{c}\text { TLBO-PS } \\
\text { (without } \\
\text { compensators ) }\end{array}$ & 1690.7170 & $\begin{array}{l}\text { Teaching } \\
\text { learning } \\
\text { based } \\
\text { optimization } \\
\text { and pattern } \\
\text { search } \\
\text { algorithms } \\
\end{array}$ & I \\
\hline $\begin{array}{l}\text { TLBO-PS (with } \\
\text { compensators ) }\end{array}$ & 1686.3069 & $\begin{array}{c}\text { Teaching } \\
\text { learning } \\
\text { based } \\
\text { optimization } \\
\text { and pattern } \\
\text { search } \\
\text { algorithm }\end{array}$ & 1 \\
\hline
\end{tabular}

\section{- Case 2: Total Voltage Deviation Improvement}

In this case, the active power and voltages of thermal units are optimized without considering the shunt compensators and the SVC controllers. The load demand to be satisfied is $684.1 \mathrm{MW}$. By using the combined mechanism search based TLBO-PS, the total voltage deviation is reduced to $\mathbf{1 . 8 0 3 8}$ p.u compared to the best value found using the standard TLBO, the corresponding total fuel cost and power loss are $2314.10(\$ / \mathrm{h})$ and 27.2976 MW, respectively. The convergence characteristic of the total voltage deviation at the final stage is shown in Fig 9, the convergence characteristics of the optimized control voltages of PV buses at specified trial are shown in Fig 10, and the voltage profiles are shown in Fig 11. Table 2 shows the optimal vector of control variables associated to this case.

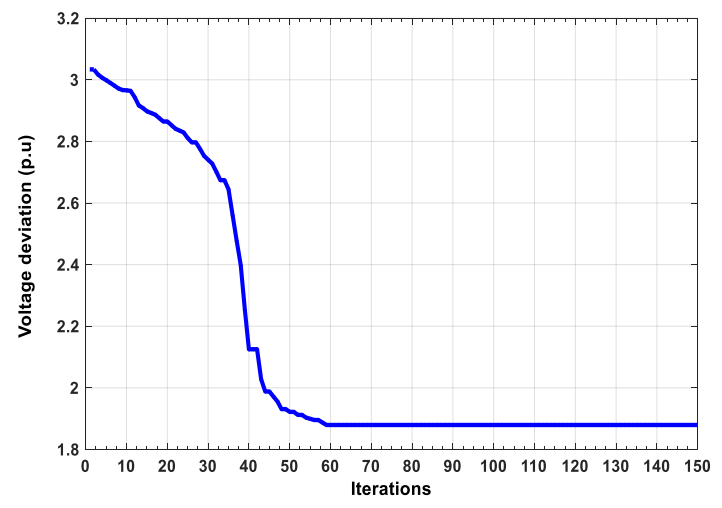

Fig.9. Convergence characteristic of total voltage deviation at the final stage.

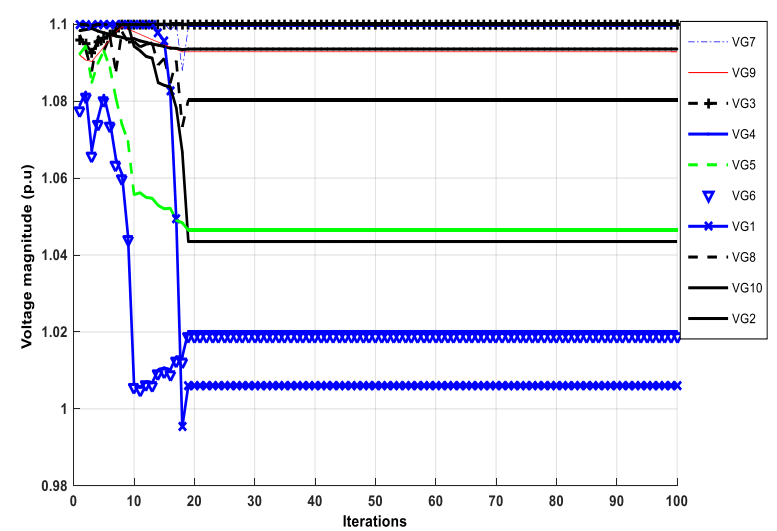

Fig.10. Convergence characteristics of generating voltages at the first stage: Case 2.

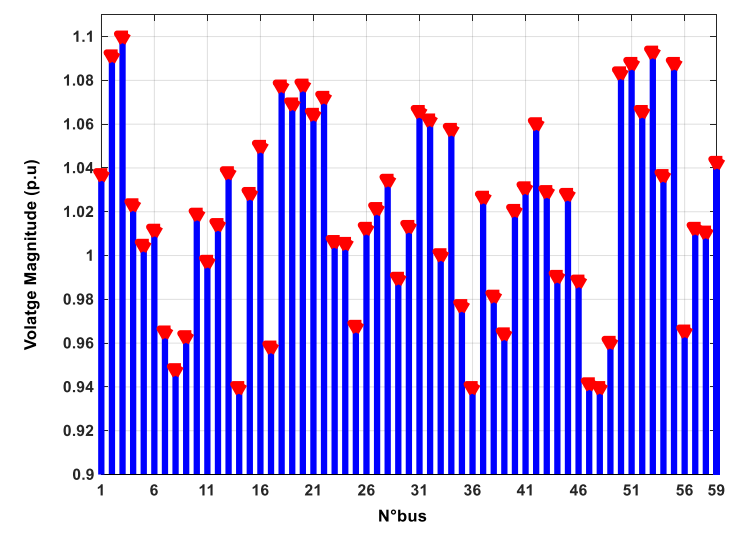

Fig.11. Voltage profiles for case 2: voltage deviation minimization.

\section{- Case 3: Minimization of Power Loss}

In this case, the total power loss is optimized by adjusting the active power and voltages of generating units. The conventional shunt compensators and the SVC are not considered. The best power loss achieved in the first stage using TLBO is 13.4598 MW. By using the combined mechanism search based TLBO-PS, the optimal total power loss achieved at the final stage, is reduced to $11.8688 \mathrm{MW}$, the corresponding total voltage 
deviation and total fuel cost are 3.0336 p.u, $1924.10(\$ / h)$, respectively.

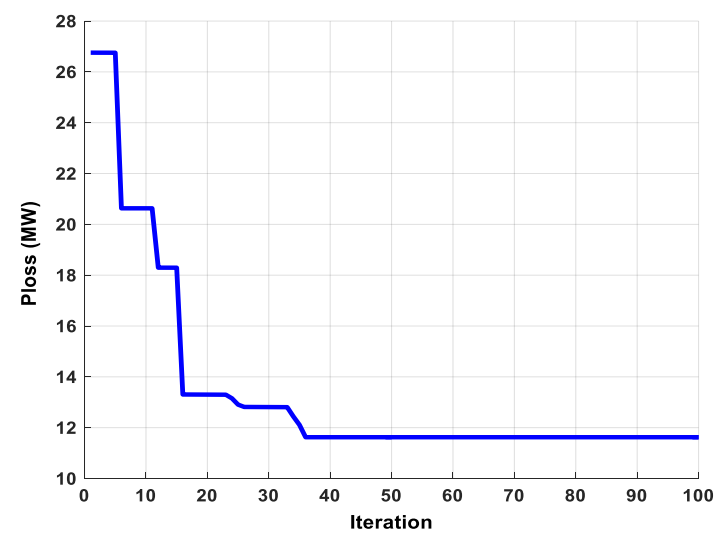

Fig.12. Convergence characteristic of total power loss during the final stage.

The main advantage of the proposed strategy is related to the dynamic database generated during search process, and this information is very useful to experts and may be exploited to achieve optimization of other specified objectives. The convergence characteristic of the total power loss at the final stage is shown in Fig 12, and the evolution of voltages of generating units during search process at specified trial are shown in Fig 13.

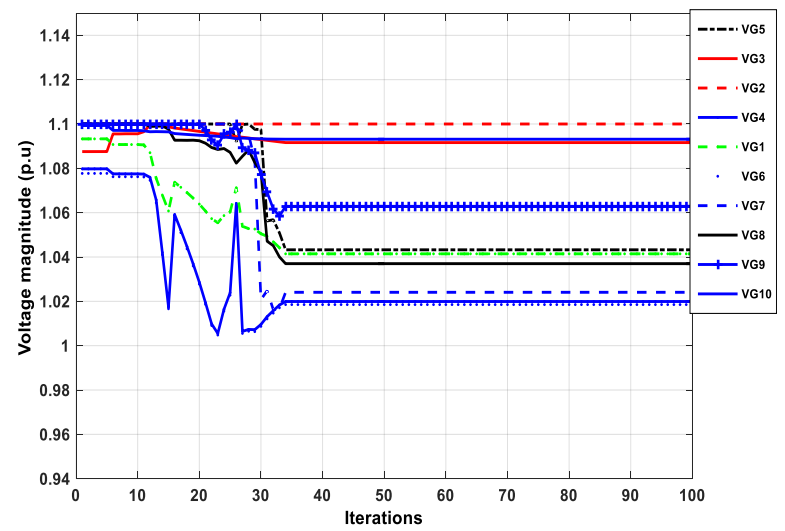

Fig.13. Convergence characteristic of generating control voltages at the first stage: case 3 .

\section{- Case 4: Voltage Deviation Improvement Considering Cost}

To make feasible decision, the experts need to determine multi compromise solutions between different conflict objective functions. In this case the main objective is to minimize simultaneously the cost and to improve the total voltage deviation. In this study, the total voltage deviation is also minimized considering the fuel cost. Table 4 shows the optimized vector control variables and the best objective function values at base load condition $(\mathrm{PD}=684.1 \mathrm{MW})$. As well shown in Table 4 , the total voltage deviation increased and the total cost decreased, the compromise solution achieved for total voltage deviation and total fuel cost are, 1.9686 p.u and $1979.4(\$ / h)$ respectively, the corresponding total transmission losses is $18.4891 \mathrm{MW}$. As well depicted in Table 2, all results related to four objective functions have been improved by considering the coordinated between global and local mechanism search during search process.

\section{- Verification of Limit Violations}

This section is investigated to verify the efficiency of a recent technique published in the literature. The optimized vector of control variables obtained by this method is injected to the power flow tool based Matpower [29]. This task allows us to verify violation constraints of all dependent variables and control variables such as, the active power of slack generator, voltage magnitudes of generators, tap transformer, reactive power of compensators.ac In this section, the results obtained by the new method named LCA are checked and exact solution are well depicted in Table 4. As we can see the optimized control variables related to voltage deviation minimization is not adequate due to violation of reactive power limits at three generating units.

Table 4. Comparative study using TLBO-PS with LCA [32]: Case 2: voltage deviation.

\begin{tabular}{|c|c|c|c|c|c|c|c|}
\hline \multirow{2}{*}{\multicolumn{4}{|c|}{$\begin{array}{c}\text { Control variables } \\
\mathrm{P}_{\mathrm{Gi}}(\mathrm{MW})\end{array}$}} & \multicolumn{4}{|c|}{ Min DV } \\
\hline & & & & \multicolumn{2}{|c|}{ TLBO-PS } & \multicolumn{2}{|c|}{ LCA [21] } \\
\hline \multicolumn{4}{|c|}{$P_{G 1}$} & \multicolumn{2}{|c|}{19.8543} & \multicolumn{2}{|c|}{9.4300} \\
\hline \multicolumn{4}{|c|}{$P_{G 2}$} & \multicolumn{2}{|c|}{10.0452} & \multicolumn{2}{|c|}{18.4200} \\
\hline \multicolumn{4}{|c|}{$P_{G 3}$} & \multicolumn{2}{|c|}{30.0452} & \multicolumn{2}{|c|}{30.0000} \\
\hline \multicolumn{4}{|c|}{$P_{G 4}$} & \multicolumn{2}{|c|}{69.0973} & \multicolumn{2}{|c|}{132.780} \\
\hline \multicolumn{4}{|c|}{$P_{G 5}$} & \multicolumn{2}{|c|}{0} & \multicolumn{2}{|c|}{0} \\
\hline \multicolumn{4}{|c|}{$P_{G 6}$} & \multicolumn{2}{|c|}{84.8640} & \multicolumn{2}{|c|}{15.0500} \\
\hline \multicolumn{4}{|c|}{$P_{G 7}$} & \multicolumn{2}{|c|}{41.6844} & \multicolumn{2}{|c|}{47.3100} \\
\hline \multicolumn{4}{|c|}{$P_{G 8}$} & \multicolumn{2}{|c|}{46.2239} & \multicolumn{2}{|c|}{15.0000} \\
\hline \multicolumn{4}{|c|}{$P_{G 9}$} & \multicolumn{2}{|c|}{93.8364} & \multicolumn{2}{|c|}{134.5000} \\
\hline & & & & & 477 & & 4100 \\
\hline & & $Q_{\min }$ & $Q_{\max }$ & & & & \\
\hline$V_{G 1}$ & $Q_{G 1}$ & -10 & 15 & 1.0261 & 10.6515 & 1.0706 & 33.5415 \\
\hline$V_{G 2}$ & $Q_{G 2}$ & -35 & 45 & 1.0804 & 41.7442 & 1.0581 & 19.6415 \\
\hline$V_{G 3}$ & $Q_{G 3}$ & -35 & 55 & 1.0891 & 38.5305 & 1.0853 & 53.7209 \\
\hline$V_{G 4}$ & $Q_{G 4}$ & -60 & 90 & 1.0122 & 80.8056 & 1.0360 & -15.4728 \\
\hline$V_{G 5}$ & $Q_{G 5}$ & -35 & 48 & 1.0272 & -32.4830 & 0.9972 & -103.7798 \\
\hline$V_{G 6}$ & $Q_{G 6}$ & -20 & 35 & 1.0106 & 32.4901 & 1.0367 & 159.8463 \\
\hline$V_{G 7}$ & $Q_{G 7}$ & -20 & 35 & 1.0159 & 16.8783 & 1.0326 & 15.3457 \\
\hline$V_{G 8}$ & $Q_{G 8}$ & -35 & 45 & 1.0200 & 24.2161 & 1.0044 & 8.5146 \\
\hline$V_{G 9}$ & $Q_{G 9}$ & -35 & 55 & 1.0496 & 42.0389 & 1.0724 & 54.9852 \\
\hline$V_{G 10}$ & $Q_{G 10}$ & -100 & 160 & 1.0823 & 34.3332 & 1.0999 & 88.7395 \\
\hline & PD & IW) & & & & & 4.1 \\
\hline & & .u) & & & & & 911 \\
\hline & Plos: & MW) & & & & & 8000 \\
\hline & Cos & /hr] & & 231 & 000 & & .0399 \\
\hline & Constrain & violat & & $\begin{array}{r}\text { All co } \\
\text { sa }\end{array}$ & $\begin{array}{l}\text { raints } \\
\text { ied }\end{array}$ & $\begin{array}{l}\frac{\text { Infeasi }}{\text { vio }} \\
\text { constra } \\
\text { power } \\
\text { units at }\end{array}$ & $\begin{array}{l}\text { e solution, } \\
\text { tion of } \\
t s, \text { reactive } \\
\text { generation } \\
1, \text { G5, and } \\
66\end{array}$ \\
\hline
\end{tabular}

Bold font with blue color indicate the best results of the proposed hybrid method-Bold font with red color indicate the violation constraints of reactive power of generators based LCA. 


\subsection{Algerian Network Planning Under Loading Margin Stability Considering SVC Devices}

For reliability operation of the Algerian power system, it is mandatory to maintain a required margin security level. Optimization of power losses or voltage deviation considering critical load growth is an important task for expert to ensure the reliability of a modern power system. In this stage, multi SVC Controllers are taken in consideration and installed at efficient locations. According to results obtained using the continuation load flow, six candidate buses (18 2536474853 ) are selected as the best locations for installation of multi SVC devices. For this scenario, the admissible limits for voltages at all buses are taken between 0.94 p.u and 1.1 p.u respectively.

\section{- Case 5: Power Loss Reduction Considering Critical Load Growth}

For this case, the electrical system is pushed to its loading margin stability, the best total power loss obtained using the proposed hybrid method is $\mathbf{2 4 . 4 4 6}$ MW at loading factor $\mathbf{1 . 4 0 2 1}$ p.u which correspond to the load 959.1766 MW, as a consequence the obtained voltage deviation is 2.3890 p.u. The convergence of the total power loss at the final stage is shown in Fig 14. The reactive power exchanged between SVC devices installed at buses (18 25364748 and 53) and the network are shown in Fig 16. All dependent variables such as reactive power limit of thermal units, voltages at all buses are within their security limits.

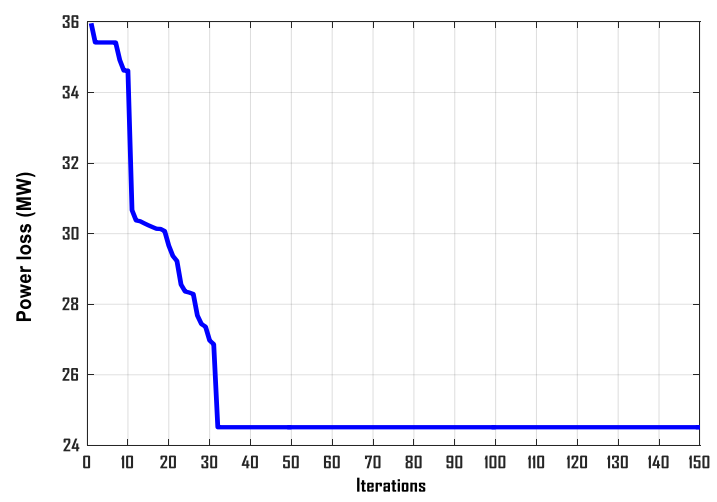

Fig.14. Convergence characteristic of total power losses: Case 5.

\section{- Case 6: Voltage Deviation Minimization Considering Critical Load Growth}

Delivering efficient energy to consumer at critical conditions is an important task for power system utility. In this scenario, the voltage deviation is optimized considering the loading margin stability. The best total voltage deviation achieved is $\mathbf{2 . 2 4 1 8}$ p.u, the corresponding total power loss is $25.1441 \mathrm{MW}$. The convergence characteristic for power voltage deviation minimization is shown in Fig 15, the amount of optimized reactive power exchanged between the SVC devices installed at buses (18 25364748 53) and the network are shown in Fig 16. The maximum load growth achieved without affecting the security constraints is 1.4021 p.u.

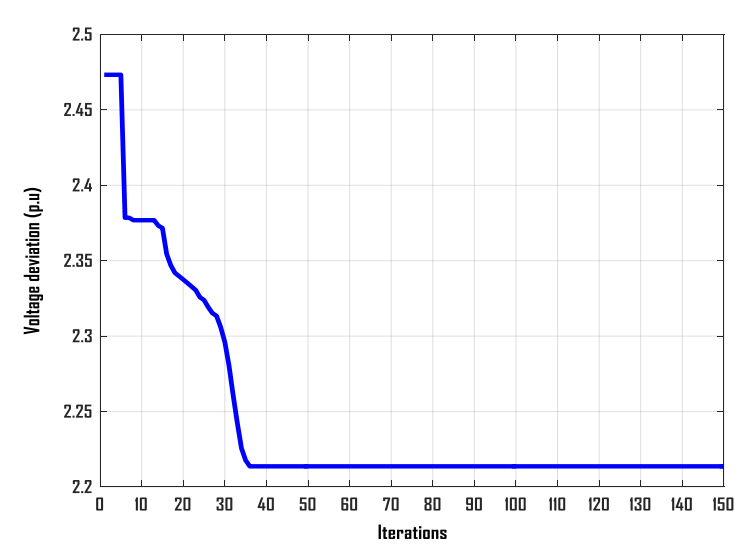

Fig.15. Convergence characteristic of total voltage deviation: Case 6.

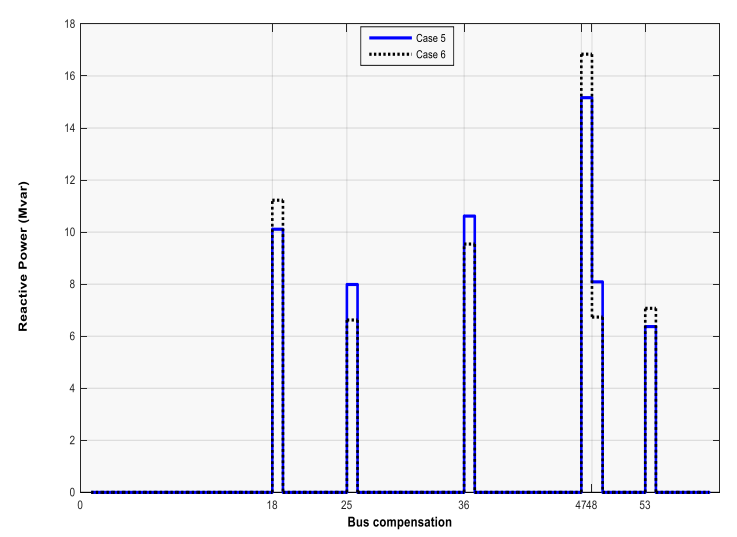

Fig.16. Amount of optimized reactive power of SVC Controllers: Cases 5-6.

\section{$>$ Network Test System 2: IEEE 118-Bus}

The efficiency of the proposed hybrid method namely TLBO-PS is tested on a large power system, the IEEE 118-bus. The IEEE 118-Bus consists of 186 lines, 54 thermal units, 14 capacitor banks, and nine tap changing transformers located at branches 8-5, 26-25, 30-17, 38-37, 63-59, 64-61, 65-66, 68-69, and 81-80 [23, 29]. The total load demand to satisfy is $4242 \mathrm{MW}$ for real power and 8777 MVAR for reactive power, the admissible limits of voltage magnitudes for all generators and transformer tap settings are taken between 1.1-0.9 p.u, the security limits for voltages at all load buses are 1.1 and 0.90 p.u, respectively. Two objective functions are considered, the minimization of power loss and the improvement of voltage profiles.

\section{- Case 7: Minimization of Power Loss}

In this case, the active power and voltage magnitudes for thermal units, tap transformers, and reactive power of SVC are optimized in coordination. In the first scenario the total power loss is optimized without considering static and dynamic shunt compensation. Firstly, the best power loss obtained using the original TLBO is 15.4834 
MW, and by applying the proposed TLBO-PS approach, the minimum total real power loss obtained is reduced to 8.9965 MW, and as a consequence the voltage deviation is increased to $5.0741 \mathrm{p} . \mathrm{u}$. In the second scenario the best power loss achieved based TLBO-PS considering the installation of shunt compensators is reduced to $\mathbf{8 . 5 8 8 6}$ MW and as a consequence the voltage deviation is increased to $\mathbf{5 . 2 8 1 9}$ p.u. As we can see the improvement of total power loss is not important by considering the integration of $14 \mathrm{SVC}$, however the reactive power delivered by generators are considerably reduced, which enhance the margin stability of the power system at critical situation (sever faults). As well shown in Fig 17, the voltage profiles at all buses are within their admissible limits. The results of this case are compared to a recent approach [23] as well presented in Table 5.

\section{- Case 8: Improvement of Voltage Deviation}

In this case, the vector of control variables to be optimized consists of active power and voltage control of generators, tap transformers and reactive power of SVC. This case focuses to minimize the total voltage deviation considering the total power loss. In the first stage, by using the original TLBO, the optimized total voltage deviation obtained is $0.6403 \mathrm{p} . \mathrm{u}$, this value is found without integration of multi SVC devices. By dynamic coordination between global search and local search during search process, the total voltage deviation is reduced to $\mathbf{0 . 5 1 3 0}$ p.u without SVC compensators and the corresponding total power loss is also minimized at a very important value $\mathbf{1 0 . 4 6 2 4} \mathrm{MW}$. As well shown in Fig 17 , the voltage at all buses improved at the near desired voltage 1p.u. All constraints such as reactive power of thermal units, apparent power transit in transmission lines are satisfied.

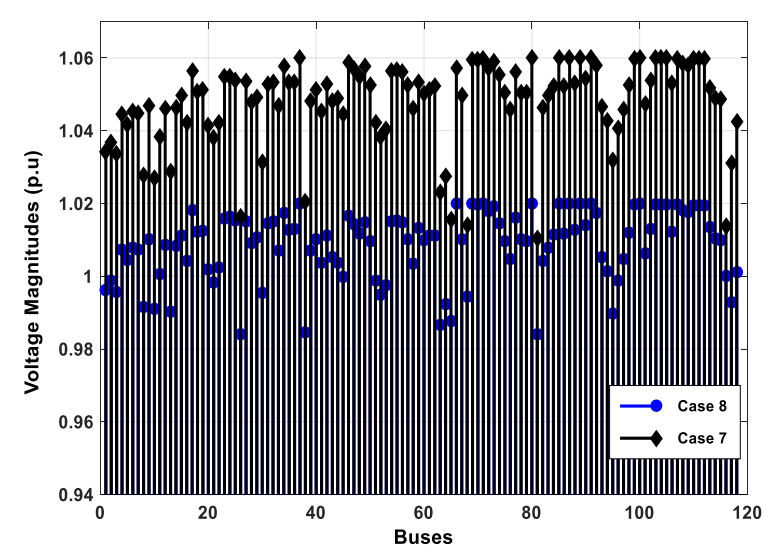

Fig. 17. Distribution of optimized voltage magnitudes: Cases: 7-8 without SVC devices.

Table 5. Comparison of optimal results for power loss and voltage deviation minimization.

\begin{tabular}{c|cc} 
& Optimal results \\
Methods & Power loss (MW) & Voltage deviation (p.u) \\
DE-APSO-PS [23] & 9.2040 & 0.4364 \\
TLBO & 15.4834 & 0.6403 \\
Proposed approach: TLBO-PS & $\mathbf{8 . 5 8 8 6}$ & $\mathbf{0 . 5 1 3 0}$ \\
\hline
\end{tabular}

\section{CONCLUSION}

In this paper, a new power system planning strategy based on coordination between TLBO and PS algorithm has been proposed and applied to enhance the solution of the security OPF considering multi SVC devices. Multi SVC compensators have been installed at suitable locations to improve the security OPF under normal condition and considering load growth. Firstly, the TLBO algorithm has the advantage of simplicity over other metaheuristic techniques and it is not necessary to adjust carefully a particular parameter, for this reason, the TLBO is treated as a global search algorithm and, secondly PS algorithm is adapted to adjust dynamically all sub optimal solutions in a feasible restricted search space. The performances of the original TLBO and PS methods are improved by using an interactive communication process during iterations and successive trials. The proposed hybrid approach has been tested and validated with the Algerian 59-bus power system and to the IEEE 118 Bus for three objective functions, the fuel cost, power loss and voltage deviation at normal condition and considering load growth. It is found from the obtained preliminary results that the proposed
TLBO-PS approach is competitive to improve the security OPF under critical conditions.

\section{REFERENCES}

[1] Dommel HW, Tinney TF. Optimal power flow solutions. IEEE Trans Power Appar Syst 1968;87(5):1866e76.

[2] Mota-Palomino R, Quintana VH. Sparse reactive power scheduling by a penalty-function linear programming technique. IEEE Trans Power Syst 1986;1(3):31-9

[3] Alsac O, Scott B. Optimal load flow with steady state security. IEEE Trans Power Appar Syst. PAS 1974:745-51.

[4] Burchett RC, Happ HH, Vierath DR. Quadratically convergent optimal power flow. IEEE Trans Power Apparat Syst 1984;103(11):3267-76

[5] Sun DI, Ashley B, Brewer B, Hughes A, Tinney WF. Optimal power flow by Newton approach. IEEE Trans Power Appart Syst 1984; 103(10):2864-75.

[6] X, Quantana VH. Improving an interior point based OPF by dynamic adjustments of step sizes and tolerances. IEEE Trans Power Syst 1999;14(2):709-17.

[7] Lai LL, Ma JT, Yokoyama R, Zhao M. Improved genetic algorithms for optimal power flow under normal and contingent operation states. Int J Electr Power Energy Syst 1997;19(5):287-92.

[8] Mahdad B, Bouktir T, Srairi K. OPF with environmental constraints with SVC controller using decomposed parallel 
GA: application to the Algerian network. J Electr Eng Technol, Korea 2009;4(1):55-65.

[9] Mahdad B, Bouktir T, Srairi K. Optimal power flow of the Algerian network using genetic algorithm/fuzzy rules. In: IEEE power and energy society general meetingconversion and delivery of electrical energy in the $21 \mathrm{st}$ century; 2008. p. 1-8.

[10] Salkut Surender Reddy, Ch Srinivas Rathnam, Optimal Power Flow using Glowworm Swarm Optimization, International Journal of Electrical Power \& Energy Systems, vol. 80, pp. 128-139, 2016.

[11] Kadir Abaci Volkan Yamacli, Differential search algorithm for solving multi-objective optimal power flow problem, International Journal of Electrical Power \& Energy Systems, vol.79, pp.1-10, 2016.

[12] Xiaohui Yuan, BinqiaoZhang, Pengtao Wang, Ji Liang, YanbinYuan, Yuehua Huang, Xiaohui Leid, Multiobjective optimal power flow based on improved strength Pareto evolutionary algorithm, Energy, vol.122, pp.70-82.

[13] H.T Jadhav, P.D. Bamane, Temperature dependent optimal power flow using g-best guided artificial bee colony algorithm, International Journal of Electrical Power \& Energy Systems, vol.77, pp.77-90, 2016.

[14] Aparajit Mukherjee, Provas Kumar Roy, V. Mukherjee, Transient stability constrained optimal power flow using oppositional krill herd algorithm, International Journal of Electrical Power \& Energy Systems, vol.83, pp.283-297, 2016.

[15] Kürşat Ayan, Ulaş Kılıç, Optimal power flow of twoterminal HVDC systems using backtracking search algorithm, , International Journal of Electrical Power \& Energy Systems, vol.78, pp.326-335, 2016.

[16] B.Venkateswara Rao, G. V. Nagesh Kumar, Optimal power flow by BAT search algorithm for generation reallocation with unified power flow controller, International Journal of Electrical Power \& Energy Systems, vol.68, pp.81-88, 2015.

[17] Harish Pulluri, R. Naresh, Veena Sharma, An enhanced self-adaptive differential evolution based solution methodology for multiobjective optimal power flow, Applied Soft Computing, vol.54, pp.229-245, 2017.

[18] K. Pandiarajan, C. K. Babulal, Fuzzy harmony search algorithm based optimal power flow for power system security enhancement, International Journal of Electrical Power \& Energy Systems, vol.78, pp.72-79, 2016.

[19] A. Ramesh Kumar, L. Premalath, Optimal power flow for a deregulated power system using adaptive real coded biogeography-based optimization, International Journal of Electrical Power \& Energy Systems, vol. 73, pp. 393-399, 2015.

[20] H.R.E.H. Bouchekaraa, M.A. Abido, M. Boucherma, "Optimal power flow using Teaching-Learning-Based Optimization technique," Electric Power Systems Research, vol. 114, pp.49-59, 2014.

[21] H.R.E.H. Bouchekara, M.A. Abido, A.E. Chaib R. Mehasni, Optimal power flow using the league championship algorithm: A case study of the Algerian power system, Energy Conversion and management (Elsevier), vol. 87, pp.58-70 2014.

[22] Tong Kang, ID, Jiangang Yao, ThanhLong Duong, Shengjie Yang and Xiangqian Zhu, A Hybrid Approach for Power System Security Enhancement via Optimal Installation of FACTS Devices, Energies 2017, 10, 1305; doi:10.3390/en10091305.
[23] Mahdad, B, K. Srairi, Multi objective large power system planning under sever loading condition using learning DEAPSO-PS strategy, Energy Conversion and Management (Elsevier), vol. 87, pp.338-350, 2014.

[24] H.R.E.H. Bouchekara, Optimal power flow using blackhole-based optimization approach, Appl. Soft Comput, vol. 24, pp. 879-888, 2014.

[25] R.V. Rao, V.J. Savsani, D.P. Vakharia, Teaching-learningbased optimization: a novel method for constrained mechanical design optimization problems, Com-put. Aided Des. 43 (3) (2011) 303-315.

[26] Miguel A. Medina, Carlos A. Coello Coello, and Juan M. Ramirez, Reactive Power Handling by a Multi-Objective Teaching Learning Optimizer Based on Decomposition, IEEE, Transaction on Power Systems, vol.28, pp. 36293637,2013

[27] K. R. Krishnanand, Syed Muhammad Farzan Hasani, Bijaya Ketan Panigrahi, Sanjib Kumar Panda, Optimal Power Flow Solution Using Self-Evolving BrainStorming Inclusive Teaching-Learning-Based Algorithm, 4th International Conference, ICSI 2013, Harbin, China, June 12-15, 2013, Proceedings, Part I, pp. 338-345, 2013.

[28] Mahdad. B., K. Srairi, Security constrained optimal power flow solution using new adaptive partitioning flower pollination algorithm, Applied Soft Computing, vol. 46, pp. 501-522, 2016.

[29] Zimmerman RD, Murillo-Sánchez CE, Thomas RJ. MATPOWER steady-state operations, planning and analysis tools for power systems research and education. IEEE Trans Power Syst 2011; 26(1):12-9.

\section{Authors' Profiles}

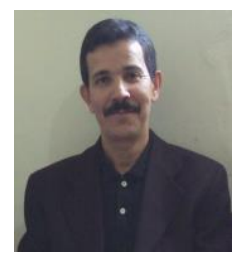

Belkacem Mahdad was born in Biskra, Algeria. He received his B.S degree in Electrical Engineering from Biskra University, Algeria in 1990, the Magister and Ph.D degrees from Annaba University and Biskra University in 2000 and 2010, respectively. He is an assistant professor at Biskra University. His research interests include Power system planning operation and control, FACTS modeling and integration in practical power system, Optimization methods, Power system stability and power system protection coordination in the presence of FACTS and renewable sources.

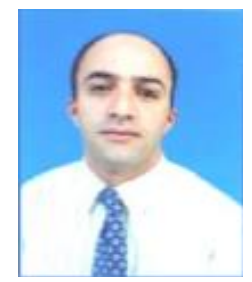

Kamel Srairi was born in Batna, Algeria, in 1967. He received a B.Sc. degree in Electrical Engineering in 1991 from the University of Batna, Algeria; an M.Sc. degree in Electrical and Computer Engineering from the National Polytechnic Institute of Grenoble, France, in 1992; and a $\mathrm{Ph} . \mathrm{D}$. degree also in Electrical and Computer Engineering from the University of Nantes, France, in 1996. After graduation, he joined the University of Biskra, Algeria, in 1998 Department. His main research interests include, power system planning and control, analysis, design, and magnetic modeling. 
How to cite this paper: Belkacem Mahdad, Kamel Srairi, " Optimal Power Flow Improvement Using a Hybrid Teaching-Learning-based Optimization and Pattern Search", International Journal of Modern Education and Computer Science(IJMECS), Vol.10, No.3, pp. 55-70, 2018.DOI: 10.5815/ijmecs.2018.03.07 